\title{
The Impact of the Structural Characteristics of Poker on Market Evolution and Competitive Dynamics in the Internet Poker Industry in Italy
}

\author{
Paolo Calvosa ${ }^{1}$ \\ ${ }^{1}$ Department of Economics, Management, Institutions (DEMI), University of Naples Federico II, Naples, Italy \\ Correspondence: Paolo Calvosa, Department of Economics, Management, Institutions (DEMI), University of \\ Naples Federico II, Campus Monte S. Angelo, Via Cinthia 26, 80126, Naples, Italy. E-mail: calvosa@unina.it
}

Received: July 24, 2019

Accepted: August 30, 2019

Online Published: September 5, 2019

doi:10.5539/ijbm.v14n10p155

URL: https://doi.org/10.5539/ijbm.v14n10p155

\begin{abstract}
The aim of this study is to analyze the impact that the specific nature and characteristics of the game of poker have had on the development of the Internet poker industry in Italy and on the competitive strategies of on line gambling operators. It facilitates the overall understanding of the different effects that the legalization of Internet gambling in Italy has had on the evolution of the poker industry, in respect to other gambling sectors. Based of existing literature, the study has shown that two distinctive features define the game of Internet poker. The first is connected to the nature of games of skill that distinguishes poker; the second, instead, is linked to the fact that Internet poker is a 'player-versus-player game', i.e. it requires the simultaneous presence at gaming tables by multiple players. In order to analyze the market dynamics of the Internet poker industry, from a methodological viewpoint the study is supported by an empirical investigation that concerned all the 'on line poker rooms' in Italy that were remote gambling licenses or sub-licensees in 2018. The results of the empirical analysis have highlighted that the progress of market sales and competitive strategies that have typified the evolution of the on line poker market in Italy seem to be strongly influenced by the specific characteristics of the game of poker. This has led to the affirmation of a distinctive structure of competition in this market, that differs from that of other categories of on line games. The empirical analysis carried out has also made it possible to show that the legalization of on line gambling, that started in 2008, has opened the Italian regulated gambling industry to competition from foreign 'Internet pure players', who have acquired a strong market position in the on line poker sector. The results of the research provide interesting indications to policy makers in the field of the regulation of on line gambling and also bring out interesting implications of a managerial nature that help to devise competitive strategies more consistent with the specific characteristics of the game of poker.
\end{abstract}

Keywords: internet poker industry, Italy, Game characteristics, competitive strategies, market evolution, internet gambling legalization

\section{Introduction}

In recent years the gambling industry in Italy has been affected by a series of changes in which regulatory and technological developments have led to a very high growth in market sales. The market data provided by the 'Customs and Monopoly Agency' (Agenzia delle Dogane e dei Monopoli), the regulating body of the Italian gambling sector, shows that in 2017 the total amount wagered in Italy grew seven-fold compared to 2003, exceeding 101 billion euros, while the Gross Gambling Revenue (GGR) - the amount wagered minus the winnings returned to the players - was almost 19 billion euros, more than tripling the 2003 values (Customs and Monopoly Agency, 2018).

One of the factors that have contributed to the growth of the sector is the choice of the Italian legislator, with the 'Bersani decree' of 2006 and the subsequent 'Abruzzo decree' of 2009, to legalize Internet gambling. As observed (Gainsbury et al., 2012, p. 1388) "the term Internet gambling is often used interchangeably with on line gambling and refers to all forms of gambling (including wagering) via the Internet through varied media including computers, mobile phones and wireless devices". The market data shows that Italian players have appreciated these new forms of remote gambling. The total amount wagered through the digital channel in Italy has grown from 1.48 billion euros in 2008, to 26.1 billion in 2017, and the GGR reached in 2017 a value of 1.34 
billion euros (Customs and Monopoly Agency, 2018).

The regulatory provisions that introduced on line gambling in Italy have meant that all the types of legal bets in Italy that were already distributed through the brick-and mortar stores - 'betting shops' and 'corners' - are now also offered via the Internet, giving rise to one multichannel distribution.

For a specific category of gaming, that of poker, the legalization of Internet gambling has, instead, allowed the creation of a practically new betting market for Italy. Until 2008, in fact, this type of game could only be accessed via land-based gambling casinos. The betting volume of this gaming sector was therefore very limited, given the presence of only four gambling houses in the Italian territory, concentrated in the north of the country, under a restrictive policy defined by the Italian legislator. The spread of the poker game in Italy is therefore the consequence of the exploitation of the connective potential typical of web based technologies, which has allowed players to be put into contact within virtual casinos that can be accessed using home computers and other mobile devices equipped with specific software programs. However, if the analysis of the evolution of the Italian regulated on line poker market is deepened, it emerges that an initial accelerated growth in sales was followed by a decisive reduction in gaming levels. In fact, the regulatory framework that has legalized Internet gambling in Italy does not yet seem perfectly aligned with the particular nature of poker games and this is probably limiting the development of the sector.

In effect, the progress of market sales and competitive dynamics that have distinguished the evolution of the on line poker market in Italy seem directly connected to the specific characteristics of the game of poker. That is in line with the indications of the studies that have revealed that the specific structural characteristics of different types of gaming are an important factor in understanding more about gambling behavior and gambling market development. It was observed that "by identifying and understanding how games are structured (i.e., game design and associated features)", it is possible to try "to unravel what makes a game addictive or what makes a game playable and therefore engaging and commercially successful" (Parke \& Griffith, 2007, p. 213-214).

This research work analysis deepens the study of the specific nature and characteristics of the game of on line poker and the impact that these characteristics have had on the development of the Internet poker industry in Italy and on the competitive strategies of on line gambling operators of this market. That is it permits the overall understanding of the particular effects that the legalization of Internet gambling has had on the evolution of this industry, in a different way to that compared with what has happened in other gambling sectors.

The specific study of the Italian market is interesting for several reasons. First, considering that the Italian regulated on line poker industry is relatively young (Internet poker was legalized in 2008), it is possible to analyze the evolutionary process of the sector starting from the moment of its birth. Secondly, there are some regulatory and distributive peculiarities that characterize this gaming market, that make it a particularly significant field of study. Thirdly, as no academic research work has yet been carried out regarding the economic-business field that has specifically examined this subsector of the Italian gambling industry.

The article is organized as follows. In the next Section a literature review concerning the structural characteristics of on line poker is carried out. Then, Section 3 specifies the aim of the study and illustrates the research methodology. Section 4 describes the results of the empirical analysis. Section 5 presents conclusions and implications of the study.

\section{Internet Gambling and the Characteristics of on Line Poker: A Literature Review}

Internet gambling has developed around the world since the mid-1990s, with the increase of percentage use of the Net and the spread of dedicated software programs for remote gambling. Specifically, it was in 1994 that Microgaming, a private software development company, started the first software for Internet gambling, which was associated, in 1995, with the creation of protocols of encrypted communication by the company CryptoLogic, which increased the security of on line monetary transactions. This is how in 1995 some gambling operators started offering on line gambling games in the 'for fun' mode, while in 1996 it opened its activities 'InterCasino', the first on line casino to accept bets with cash winnings. By the end of 1996, it is estimated that 15 on line websites were already accepting bets with cash winnings around the world. This number progressively increased to 650 by the end of 1999, to reach 1,800 in 2002 (Wood \& Williams, 2007; Williams, Wood, \& Parke, 2012).

Over time, players have shown an appreciation for the advantages of betting via the Internet, driving the international growth of a market characterized by specific evolutionary dynamics with respect to that of traditional gambling, that being managed by brick-and-mortar retailers. In this regard, the Internet gambling market worldwide reached a value in 2017 of almost 46 billion U.S. dollars, a value that, according to estimates, 
could double in the coming years, reaching more than 94 billion U.S. dollars. This being thanks to factors such as the advancement of available technology (smartphones, apps and social networks), a higher trust of gamblers paying on line, and a greater digitization in different regions of the world (Statista, 2018).

The accelerated growth of on line gambling has become the subject of attention in the field of academic studies. Some researchers (among others: Gainsbury et al., 2015; Hing et al., 2014; Gainsbury, 2012; Williams, Wood, \& Parke, 2012; Forrest, 2012; Pilling \& Bartlett, 2012; Morgan-Busher, 2012; Wood \& Williams, 2007) examined how the possibility of offering games via the Internet has impacted on the purchasing behavior of consumers and on the dynamics of development in the gambling industry at international level. They have shown, in general, that remote gambling: has led to a transition of players from land-based gambling houses to interactive gambling; making it possible to connect players at a low cost, creating new forms of betting; and has also allowed new companies specializing in the sale of on line games to enter in various geographic gambling markets, increasing competitive pressure in many national contexts. Furthermore, this research has highlighted the high social impact and risks of addictive gaming behavior associated with the diffusion of Internet gambling.

The aforementioned studies have examined the phenomenon of on line gambling mainly in the form of general overviews. A more limited number of research contributions have instead analyzed the specific characteristics of on line gambling markets and how the particular structural features of different types of gaming have impacted on market evolution.

Focusing our attention on the on line poker industry, it can be observed that it was born at the end of the $90 \mathrm{~s}$, in the wake of the spread of on line casino games at an international level. Starting in the early 2000s, there was a shift from an introductory phase to one of a sustained growth in the sector. The turning point is identified as the 'Moneymaker effect'. This term was created after Chris Moneymaker, a 27-year-old amateur poker player, won the 2.5 million dollar prize at the 2003 'World Series of Poker', inspiring potential players and making them believe that it was possible for anyone to get rich by playing poker at home via computer (Mudrik, 2017; Howard, 2006). Starting from that event there has been a general increase in awareness of Internet poker in the world. This being also thanks to the combined effect of other factors, such as: the continuous improvement of Internet technologies and gaming software; the entry into this betting market by new operators who had made huge investments in marketing to promote their 'on line poker rooms' (Pilling \& Bartlett, 2012); the great television exposure that tournament poker received (Schiavone, 2010).

In the academic field, studies on on line poker have focused mainly on the analysis of the relationship between remote gambling characteristics and the risks of problematic or pathological gambling behavior (Note 1).

Another research group has instead focused on the examination of a specific feature of the game of poker (Note 2) which impacts differently, in respect to other betting categories, on the 'playing strategy' and on the regulatory choices adopted by the institutional regulators of the game. These studies have tried to answer the question whether on line poker is a game of skill or a game of chance. As observed (Fiedler \& Wilcke, 2012, p. 5), "the answer to this question is especially important from a legal perspective as most jurisdictions legalize games of skill", while they regulate, or forbid, games of chance. Even if this has not always given consistent results, most of these investigations (DeDonno \& Detterman 2008; Hannum \& Cabot, 2009; Fiedler \& Rock 2009; Schiavone, 2010) have shown that for poker games, unlike other 'passive games' in which the outcome depends entirely on chance (like slot machines or lotteries), the skill of the player has some relevance. In other words, for this game the chances of winning, despite being primarily conditioned by the element of luck, seem to increase, in the long term, in relation to the player's possession of knowledge of mathematical, probabilistic and betting-strategy-related concepts. These considerations apply to poker played in 'live mode' and to that played via the Internet. As noted, in fact, the only skill that "cannot be transferred to the on line game is the player's ability to read an opponent's body language because of the fact that they are not in the physical presence of each other" (Schiavone, 2010, p. 9). However, this aspect seems more than offset by another differential feature of on line gaming compared to that of 'live play'. If it is true, in fact, as demonstrated (DeDonno \& Detterman, 2008), that in the game of poker chance predominates at the level of playing one hand, but the player's skills determine whether they will win or lose after playing 100,000 hands, on line gambling enables the player to increase the number of hands played in a specific period of time respect to physical play at land based casinos. This being thanks to a reduction of the time required for carrying out individual hands of play and the possibility of playing on multiple virtual gaming tables simultaneously. This makes it possible to reduce the relevance of the chance component more quickly in defining the outcome of the game (Fiedler \& Rock, 2009), as well as developing gaming skills faster (Eroukmanoff, Costes \& Tovar, 2014).

This characteristic of the game of poker has had an impact, from one side, on player's buying behavior and on 
market development and, from the other side, online poker regulation policies.

Regarding the first aspect, it emerges that the number of players who can access on line poker who have the skills required is more limited compared to the games based only on elements of luck, which do not require special gaming knowledge. This causes the potential market for poker games to be lower than that of pure luck games.

Regarding the aspect of the regulation policies, it is instead useful to point out that throughout the world public authorities adopt different regulatory approaches in the field of Internet gambling. Some countries - such as Italy - have legalized all types of on line gaming. Others are divided between a regulatory approach that prohibits any form of Internet gambling and a selective regulatory approach, under which different legalization forms are adopted in relation to different types of game (Fidone \& Linguiti, 2013; Williams, Wood, \& Parke, 2012; Gainsbury \& Wood, 2011). The recognition of poker as a gaming category in which the player's skill plays a certain role - after the element of chance - is an important factor that can influence the decisions of state authorities in the consideration of the legality of on line poker (Miller, 2013; Grohman, 2006).

Another aspect - not yet sufficiently analyzed in the literature - that distinguishes on line poker from other categories of gambling and affects the strategies of gambling operators, is relative to the fact that Internet poker is a 'player-versus-player game'. That is the game requires the simultaneous presence at the gaming tables of multiple players. This feature means that, for on line poker, unlike games for which individual players can bet regardless of the presence of other players (such as, for example, slot machines or sports betting), the quality of the customer experience is linked to the ability of on line 'card rooms' to involve a critical mass of players at any given time through their digital platforms, i.e. to guarantee what the sector's specialists call 'player liquidity' (Koch, 2015; Bush, 2015; Miller, 2013). Internet poker websites, therefore, must adopt strategies aimed at increasing their player base, in order to prevent players from moving to other gambling operators who, thanks to high player liquidity, guarantee a better betting experience. As it will be possible to investigate further below, in many cases this objective is achieved by joining gaming networks that connect - through software platforms provided by specialized service providers - the customers of various gaming operators (Miller, 2013), even if regulatory aspects can limit customer sharing between different poker rooms, especially if they come from different countries (Busch, 2015).

\section{Aims and Methodology}

The aim of this work is to analyze the impact that the legalization of Internet gambling has had on the evolution of the Italian poker industry, in a different way to that compared with what has happened in other gambling sectors. In particular, the examination of the way in which the nature and specific characteristics of Internet poker have influenced the growth of the Italian on line poker market and the competitive strategies of on line gambling operators.

From a methodological point of view the information from a series of secondary sources (academic journals, market research, gambling press agencies, specialized reviews) was used in order to examine the effect that the legalization of Internet gambling has had on the developmental dynamics of the poker sector in Italy. In particular, the official market data provided by the Customs and Monopoly Agency and by the 'Journalistic agency on the gambling market' (Agimeg) has been collected and processed for the years between 2009 and 2018 , thus allowing analysis of the life cycle of the poker sector starting from the initial phase.

An empirical research work was then carried out in order to analyze how the specific nature and characteristics of on line poker are influencing the evolution of the Italian market and the competitive strategies of gambling operators. This empirical research took the following steps:

1. To identify all the companies that have the direct license necessary for remote gambling issued by the Italian Customs and Monopoly Agency (Note 3);

2. To identify, for each of the direct licensee companies, the 'on line poker rooms' managed by them or by any sub-licensee gambling operators (poker skins) (Note 4). The analysis showed that the number of on line gambling poker rooms active in Italy at the end of 2018 (both licensees and sub-licensees) amounted to 156;

3. For each of the on line poker rooms active in Italy an in-depth elaboration and analysis was carried out on: a) the information reported on the company sites (for the gambling operators the Internet site represents a virtual store through which poker games are provided and the characteristics of the company and the assortment of games offered are communicated to the potential customer); b) official market data (type of gambling concession, market shares, etc.) provided by the Customs and Monopoly Agency and by the Journalistic agency on the gambling market (Agimeg); c) data coming from a series of secondary sources (specialized magazines, market 
research, etc.); d) information obtained through direct contacts (via email or telephone) for the purpose of acquiring data that did not result from the other sources used.

\section{Results and Discussion}

\subsection{The Birth and Development of the on Line Poker Industry in Italy: Regulatory Aspects and Market Data}

The development of the Internet gambling industry started in Italy, in an embryonic form, between the end of the $90 \mathrm{~s}$ and the beginning of the 2000 s, thanks to two regulatory interventions that gave road to an experimental remote gambling collection by some authorized dealers (Sbordoni, 2010). It is then with the 2006 Bersani decree that "in order to counter the spread of irregular gambling and illegal, tax evasion and avoidance in the gaming sector, as well as ensuring the protection of the player" (Note 5) the possibility was given to the "Autonomous Administration of State Monopolies' (Agenzia autonoma Monopoli di Stato), now Customs and Monopoly Agency, to regulate new typologies of gambling.

The Bersani decree has implemented what is called a liberalization of Internet Gambling. As observed (Mataluni, 2013), this expression must be correctly framed within the framework of the discipline of Italian law. The decree in question has not, in fact, eliminated the system of titles of authorization at the base of the legal gaming system in Italy, but provided for the need, for remote gambling, of a license issued by the Customs and Monopoly Agency only to those who already have a special qualification that allows gambling activities. This has opened the Italian legal market to foreign operators who have obtained the release of the license thus being authorized to sell gaming in other countries. Since 2006, by virtue of the Bersani decree and the subsequent 'Abruzzo decree' of June 2009, the Italian Customs and Monopoly Agency has issued a series of regulations for the discipline of on line gambling, which allowed games already offered through the land based venues to be sold via the Internet (Sbordoni, 2010). The new rules have also allowed the introduction of some new types of games exclusively offered by on line websites, allowing the establishment in Italy of a new sector of betting, that of on line poker.

The legalization of on line poker has however had a different impact in Italy than that which has happened in other countries. In Italy, in fact, the possibility of offering poker games via the Internet has boosted the growth of a gambling market that until then had only residual dimensions. The betting volumes of poker were in fact extremely contained, given the presence in Italy of only four authorized casinos for the sale of poker games (Venice Casino, San Remo Casino, Campione d'Italia Casino e Casino de la Vallè-Saint Vincent). These casinos, controlled by local public authorities, are concentrated in the north of the country, near the territorial borders. This obliged players to bear high costs (in terms of time and money) in order to reach the land-based casinos and stay overnight in order to play. The legalization of on line casino games, including poker, allowed players to access these types of games via gambling websites, benefiting from advantages in terms of convenience and speed of gambling and the reduction in monetary and non-monetary costs for allowing access to gambling. The players, in fact, can now enter into contact with each other within the sphere of virtual casinos, from the comfort of their homes, thanks to the exploitation of the connective potential typical of Internet technologies. The spread of on line poker in Italy has therefore transformed a niche business, accessible only for a limited number of high-income players through the four gambling houses, into a mass market business. Just observe that in 2018 the total amount wagered in poker games in the Italian land-based gambling casinos amounted to just 8 million euros, while that of on line poker was equal to a total of almost 3 billion euros, to which it paid a GGR of around 147 million (Agimeg, 2019a; 2019b). Indeed, the spread of on line games, not just those connected to poker, has had a negative impact on the activities carried out by the four public gambling houses active in Italy. If we consider that overall in 2018, these houses raised approximately 244 million euros, halving the revenues obtained in 2006, a year before the start of legalization of remote gambling. The crisis of Italian land based casinos is also shown given the bankruptcy of the company that controls of one of the four gambling groups in 2018, that of Campione d'Italia (Agimeg, 2019c).

Deepening the examination of the Italian market data collected in 2018 by the Customs and Monopoly Agency in relation with the different types of poker games offered, it is possible to point out that 'cash poker' has registered in total an amount wagered equal to 2.3 billion euros and a GGR of just over 65 million euros. For 'tournament poker', instead, the total amount wagered has recorded a value of approximately 650 million euros to which a GGR of 82 million euros was paid (Note 6).

If we analyze the market data in terms of trends - shown in Figure 1 - it emerges, however, that an initial accelerated development of the on line poker industry in Italy - also fueled by the novelty of such games - has been followed by a marked reduction in gaming levels, which were more than halved in 2018 , if compared with the 2010-2012 peak data. 


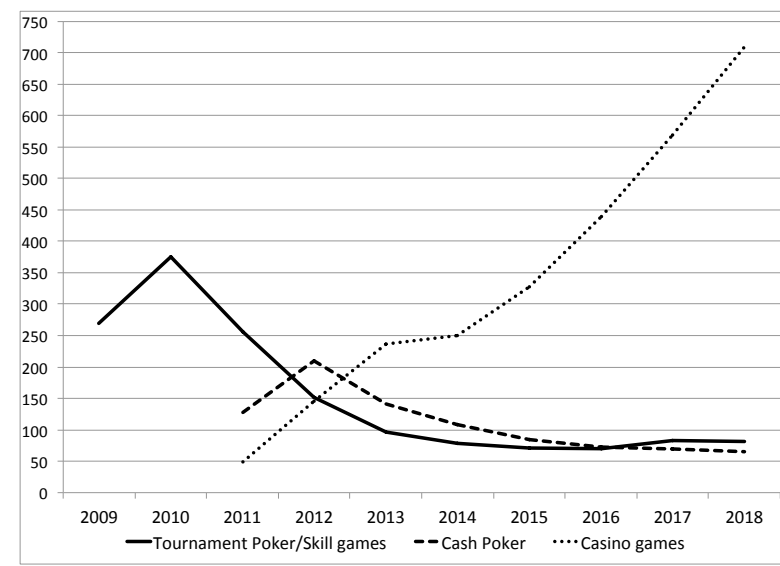

Gross Gambling Revenues (GGR)

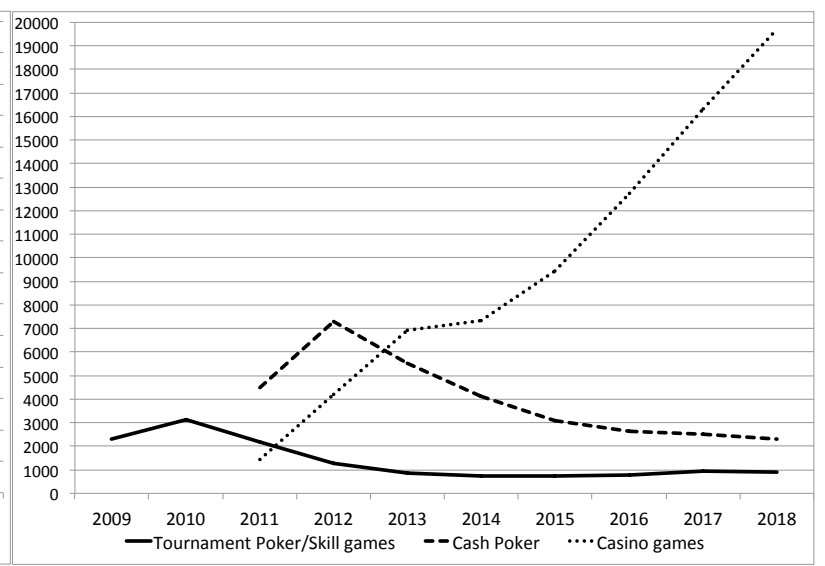

Total amount wagered

Figure 1. Gross Gambling Revenue and Total amount wagered in on line poker games and on line casino games. Italian regulated market. Years 2009-2018 (millions of euros)

Source: our processing of data from Italian Customs and Monopoly Agency and Agimeg.

The sales trend is the consequence of several factors, which have acted together in limiting the complete development of the Internet poker market.

First, there has been a process of competition between different types of on line gaming. In Italy, tournament poker was legalized first, and 'cash poker' and other 'on line casino games' only after three years received the same treatment. The first on line tournament poker game was played in September of 2008 with the Italian operator 'Gioco Digitale', which was followed by the rapid growth of the business, that reached a peak of amount wagered higher than 3 billion euros in 2010, which corresponded to a GGR of over 370 million.

The introduction to the market in 2011, under the 'Abruzzo decree', of on line cash poker and other on line casino games has made many players take their bets elsewhere, as happened also in other foreign markets, towards these new forms of gaming (Autonomous Administration of State Monopolies, 2012a). This emerges clearly by observing the trend of the sales graphs shown in Figure 1. It turns out, in fact, that cash poker achieved very rapid initial sales growth. In 2012, one year after its legalization, the total amount wagered had exceeded 7 billion euros, which corresponded to 209 million euro in terms of GGR. This growth went on to subtract gambling volume from the tournament poker mode, which was also thanks to its novelty.

In turn, cash poker, as of 2013, has also been affected by a reduction in betting levels, because of the competition of on line casino games other than poker. In fact, from Figure 1 it emerges that, since their introduction on the market, on line casino games have had both the amount wagered and GGR levels steadily increase, reaching in 2018 respectively the values of 19.7 billion and 710 million euros.

The preference of Italian players towards this type of on line gaming is linked to the greater speed of play, as well as the different nature of game compared to those of poker. While, in fact, on line casino games can be defined as a 'games of chance', i.e. games for which the win is a consequence of purely aleatory factors as they are based on the outcome of random combinations (Note 7), the poker games, as already highlighted, are instead predominantly considered 'games of skill', as the probability of winning is also correlated to the ability of the player and not only to the aleatory element (Hannum \& Cabot, 2009). Indeed, poker is a game that requires specific skills, as well as the ability to calculate precise mathematical probabilities and to apply advanced strategic concepts and methods to win (Schiavone, 2010). The group of potential players is therefore much larger for a game based only on elements of luck than one for which the chances of winning are also linked to particular knowledge and skills.

Beyond the competition of on line casino games, there is another aspect connected to the nature and specific characteristics of the game of poker that seems to have contributed significantly to the slowdown of the growth in sales of the poker game in Italy. As, in fact, explained in greater depth in the following paragraph, which describes the distinctive features of the different gambling typologies offered in the Italian on line gambling market, the particular nature of poker means Internet technologies have a different impact on the quality of the gaming experience compared to other forms of betting, and this aspect, united together with particular regulatory 
factors, has substantially affected the development of the sector in Italy.

\subsection{On Line Gambling Typologies in Italy: The Impact of the Internet on Gaming Experience in the Poker Sector and the Relevance of 'Player Liquidity'}

As already pointed out, starting from the 2006 Bersani decree, a series of rules were approved which meant that in Italy all types of bets already legally offered through the traditional brick-and-mortar channels (Sport betting, Bingo, Horse-racing betting, Scratch and win, Lottery, Lotto, etc.) could also be distributed via the Internet. For these games, Internet gambling allowed us to transition part of bets made at betting shops to the digital network. Some customers have chosen the new on line betting channel because it is more convenient and faster than the physical one. This also has the added advantage of being able to play 24 hours a day, thus not having to respect the opening hours of the land-based channels (Wood \& Williams, 2007; Gainsbury et al., 2012). As shown by market data, however, for the most part of traditional games the number of players who use the Internet to access gambling is still quite contained compared to those who turn to the land based distribution network (Note 8). Indeed, for traditional games the Internet distribution channel has become a complementary way to access gaming in specifics occasions of use.

Alongside the traditional games described above, the legalization of on line gambling has also allowed the introduction to the Italian market of new games that, outside of the four land-based authorized casinos, are offered exclusively via the Internet. This refers to the introduction of poker games and casino games that occurred in 2008 and 2011 (Note 9).

For the poker game, the Internet has represented a critical element for sales development. To understand this, we need to describe the features that distinguish poker from other on line games. Poker is, in fact, a player-versus-player game that uses the Internet to allow players, by accessing authorized gambling websites, to compete remotely with other players at virtual gaming tables, without having to travel to a venue and by only using computer devices.

More specifically, 'tournament poker' is a totalizator game. That is, bettors pay a fixed fee that flows into a prize pool, that is then divided between the winners after taxation and the profit margins of gambling operators. For this type of bet, the quality of the gaming experience is strongly conditioned by the level of 'player liquidity', i.e. the number of players who participate in any tournament. Only if you connect a large number of players at all hours of the day it is possible, in fact, make sure that, at any time, a single player can find other people in the on line poker room with which to compete, thus creating attractive price pools.

A very similar argument is valid for 'cash poker'. While not a totalizator game (as the amounts played do not flow into a prize pool distributed among bettors), the gaming experience is influenced by the possibility of finding people at any time with which to compete at the poker tables, at the different betting levels proposed. Therefore, also for this type of poker, player liquidity is very relevant and has a significant impact on the customer selection of a specific poker website.

For the other categories of gaming that can be provided exclusively via the Internet, that of 'on line casino games' (whose main game in terms of betting volume is that of on line slot machines), they stand out clearly from those of poker in the sense that they do not fall into the category of 'player-versus-player games'. Bettors, in fact, play individually and their own probability of winning, as well as the consumer experience, is not influenced by the on line contemporary presence of other players. For these games, therefore, 'player liquidity' is not relevant and the Internet does not play the role of 'connector' of players, as determined in the game of poker (Note 10).

\section{3 'Shared Liquidity' and 'Network Approach' in the on Line Poker Industry in Italy: Stand-Alone and Network Platforms}

The peculiar characteristics of on line poker games as described above tend to influence industry competition in a different way from that which happens in other betting sectors. For on line poker websites, success is more connected to the ability to continuously involve a critical mass of players, than to the level of sophistication of the gaming software or to other competitive factors (Koch, 2015).

The extreme relevance, for Internet poker card rooms, of reaching a high player liquidity represents the main reason why many gambling operators that have the direct license for remote gambling in Italy have joined poker networks that connect - through software platforms provided by specialized service providers - the customers of different on line poker rooms. In fact, joining the network allows them to reach a high level of shared liquidity, that is to share a mass of players sufficient enough to create a satisfying gaming experience (this aspect is not relevant for other on line casino games). To this main motivation we can also add the possibility for gambling operators, adhering to their networks, to continuously have secure and robust software (to guarantee the money 
invested by players and to support the load of thousands of users connected simultaneously on the gaming platform), that is managed by a company specialized in the development of software programs for gambling.

It should also be noted that in the Italian regulated Internet gambling industry not only companies that have a direct license issued by the Italian Customs and Monopoly Agency can operate, but also companies affiliated with an authorized dealer. They can rely on the main license of the gaming operator partner and therefore take on the role of sub-licensees. These companies - called 'poker skins' - are usually small and, thanks to the affiliation, they can overcome a series of barriers that make it difficult to enter the market. The affiliation, in fact, allows first of all the bypass of the legal barrier represented by necessity obtaining a proprietary gaming license, relying on the sales right of the licensee. Secondly, affiliation allows quick access to software that is safe and certified, necessary to offer on line games - even being able to customize them - without bearing the high investment costs necessary for their development. Thirdly, with this affiliation the poker skins can join the gaming network of the licensed operator, thus linking the players of their poker rooms with those of other on line poker rooms, in order to reach a sufficient liquidity, thus providing a satisfying betting experience, difficult to achieve individually. Naturally, the poker skins are able to obtain sub-licensing and access to the described benefits allocating to the licensee a percentage of its profits and fees.

In summary, as graphically described in Figure 2, in the on line poker industry in Italy two different approaches in the supply of games coexist.

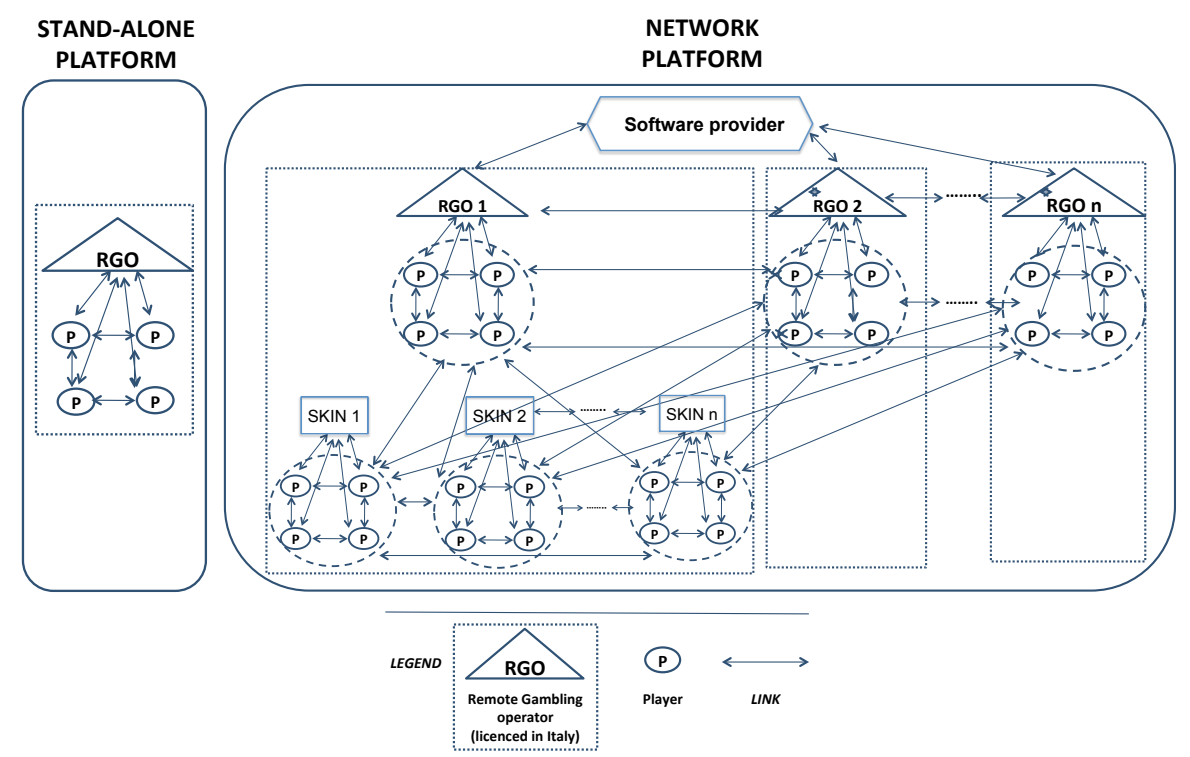

Figure 2. The approaches for providing on line poker games: Stand alone platforms vs. Network platforms Source: our elaboration.

The first approach (shown on the left in Figure 2) is the one adopted by some operators with direct concessions that operate on the market through a 'stand-alone' software platform. Such companies provide poker games via an owned software program, which connects via the Internet only those players who have joined their single poker room.

A second approach (represented on the right in Figure 2) is instead that followed by the remote gambling operators (RGO) who have a direct license and adhere to a gaming network based on one software platform developed by a specialized IT company. This network puts into contact in real time the players of their on line poker room - and any connected sub-licensing on line poker skins - with those of other licensed on line poker rooms (and associated poker skins), thus increasing the 'liquidity pooling'.

To understand how this network-based approach has spread in the on line poker sector, empirical research was conducted to examine the different gaming networks active in the Italian market and how gambling operators are distributed in the adoption of the two different approaches described. To this end, first all the companies that have the license for remote gambling have been identified, as released by the Italian Customs and Monopoly Agency. For each one, it was then identified any connected sub-licensee 'on line poker skins'.

The analysis showed that the number of on line poker rooms active in Italy at the end of 2018 (both licensees and 
sub-licensees) amounted to 156 . For each of these poker rooms was then carried out an in-depth analysis and elaboration of a series of relevant data and information, as indicated in the description of the research methodology.

The results of the empirical survey, graphically summarized in Figure 3, show that in Italy in the on line poker industry licensee operators (and sub-licensee poker skins associated with them) mostly adopt a network approach.

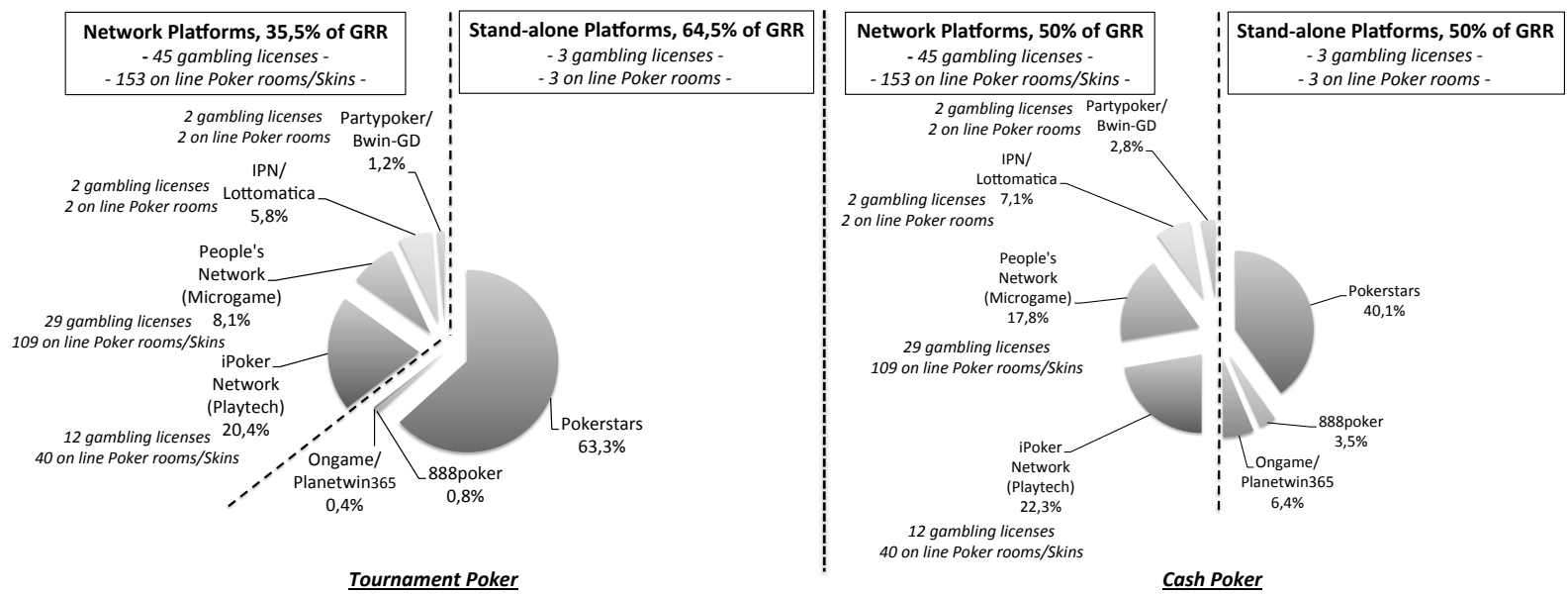

Figure 3. The results of the empirical research. The on line poker rooms active in Italy divided by the type of software platforms (Network/Stand-alone). Numerical data and Gross Gambling Revenue. Italian market, 2018

Source: our elaboration on data from Italian Customs and Monopoly Agency and Agimeg。

From Figure 3 it first emerges that as many as 153 on line poker rooms in Italy, which refer to 45 gambling licenses, are part of four Poker networks: Ipoker/Playtech, People's Network-Microgame, IPN/Lottomatica, Partypoker/Bwin. These companies, and their networks, control a total of 35.5 percent of the GGR of on line tournament poker, and half of the GGR of on line cash poker. The most relevant gaming networks in terms of sales are Ipoker and People's network. Playtech, a leading group for the supply of on line gambling software, manages the first. This group, founded in 1999, developed the Ipoker network starting in 2005, making its entry into numerous regulated markets around the world. It controls just over 20 percent of the GGR of on line tournament poker and 22.3 percent of the GGR of on line cash poker, thanks to the adherence to the gaming platform of 12 licensed gaming operators, to which 40 on line poker rooms are referred. The second network in terms of GGR, People's Network, is managed by Microgame, an Italian IT company that has been operating since 1999 in the BTB gambling market through the provision of advanced software for on line gaming. Through the BOS gaming application platform created by the company, the network involves as many as 109 on line poker rooms, many of which are small, which refer to 29 gambling licenses. These gaming operators control a total of about 8 percent of the GGR of on line tournament poker and the 18 percent of the GGR of on line cash poker. The other two active networks in Italy are IPN/Lottomatica and Partypoker/Bwin. In reality they can be classified as hybrid networks. IPN/Lottomatica is in fact based on Boss Media software, controlled by the ITG/Lottomatica Group, that is the owner of the two poker rooms that operate under license through this network. The same goes for the Partypoker/Bwin network. The company that provides the software platform for the gaming (Partypoker) and also that which controls the main poker room that adheres to the platform (Bwin) having merged in 2011. In addition, the second poker room joining this network (Gioco Digitale) was acquired in 2009 by Bwin. The decision to classify these gaming platforms in the network category is linked to the involvement of each of them with two different operators with gaming licenses that share players. In addition to this, it is because these networks also operate abroad, providing their software platform to other gaming operators, as was also happened in Italy few years ago.

Moving on to the analysis of on line gambling operators that operate through a 'stand-alone approach', shown by Figure 3 again, it emerges that there are only three, even if they control a very large percentage overall of the GGR of tournament poker - 64.5 percent - and the remaining half of GGR of cash poker. Among stand-alone gaming platforms it is clearly highlighted the dominant position in the market of Pokerstars, which controls 63.3 percent of the GGR of tournament poker and about 40 percent of the GGR of cash poker. This platform is 
controlled by Rational Group Ltd., a foreign company established in 2001 and owner of the PokerStars and Full Tilt Poker brands around the world. In 2014 the Rational group was acquired for 4.9 billion dollars by Amaya Gaming Group Inc., a Canadian company that holds a relevant position in the Internet gambling market, giving rise to the Stars Group, the largest on line poker platform in the world (Heitner, 2017).

It should also be noted that all the gaming platforms described operate at the international level (excluding the People's Poker Network). This indicates, as detailed below, that the competition in the on line poker industry has now developed between networks and gaming operators that act in different countries. In this regard, a very important underlying aspect is that, thanks to the fact of operating in more than one geographical market, a gaming operator can connect in poker games - where standards allow it - players from different countries who can join their gaming platform. This facilitates the increase of player liquidity which, as already reported, has a positive impact on the gaming experience of the players and, therefore, favors an increase in the volume of games. As noted (Koch, 2015, p. 66), in fact, "the best way to ensure 24/7 liquidity is to offer a large number of players across time zones through international liquidity sharing".

These considerations bring out one of the main factors that held back the complete development of the on line poker industry in Italy. In fact, in the Italian regulated market the legislation forbids the gaming platforms connects Italian poker players with those of other nationalities using the same company Internet platform abroad. This therefore prevents the on line poker rooms operating in Italy from sharing an 'international liquidity', that is so crucial in offering the players a particularly attractive gaming experience.

Moreover, this problem does not only affect Italy. Indeed, many states have different rules on the subject of gaming licenses, betting taxes, as well as various standards for financial transactions and player protection from gambling addiction. Given these differences, there are great difficulties in cross-border play. In fact, in July 2017 the gaming regulators of Italy, Spain, France and Portugal signed a preliminary agreement to create a unified EU gambling market, which would allow companies to access 'shared liquidity'. According to the objectives of the agreement, an Italian poker player could have competed on an '.eu platform' with Spanish, French and Portuguese players, thus increasing the number of users present at any time on the gaming platforms and, consequently, the capital circulating, with the likely effect of increasing the number of gaming tables and tournaments, as well as the value of total prize money up for grabs (Agimeg, 2017). Subsequently, a series of considerations on the aspects connected with anti-money laundering controls and fiscal factors, as well as a change in political guidelines in the gambling sector, have blocked the development of this initiative for the Italian market. The other signatory countries in 2017 of the preliminary agreement (Spain, France and Portugal) gave rise to the launch in 2018 of 'international shared liquidity' in poker. The preliminary market data recorded in these countries resulting from the creation of the unified on line poker market indicates a very positive trend in the growth of the sale of poker games, although experts predict that for complete detection of effects after this change it is necessary to wait a longer period of time.

\subsection{Internet and Transnational Competition: The Leadership of Foreign Companies in the on Line Poker Industry in Italy}

The considerations just made help to understand another aspect that characterizes the competitive dynamics in the on line poker industry. This refers to the opening of the market to foreign operators that has distinguished the evolution of this gambling industry in the last few years. In Italy already before the beginning of the legal collection of on line poker games in 2008 , several foreign companies operated via the Internet as part of a gambling market that was not expressly authorized, thus leveraging on the specific features of on line gambling - which allows you to deliver at a distance, beyond national borders, gaming services - and on the lack of a clear regulatory framework, as "to the regulations dictated by physical gaming, a complete liberalization was opposed, due to the absence of regulations, in the on line sector" (Mataluni, 2013, p. 131).

In fact, the rules that have legalized Internet poker in Italy have also authorized foreign companies to operate under license in this sector. The regulated market for on line poker was therefore affected by the entry of numerous foreign gambling operators that quickly acquired significant competitive positions, taking advantage of the technological and marketing skills, which were gained in other nations that had already been active for years.

To understand how much the regulated Italian on line poker market has been opened up to the competition of foreign operators, empirical research has been carried out aimed at examining - relative to those companies that have had a license issued by the Italian Customs and Monopoly Agency for remote gambling which were active at the end of 2018 - how the GGR is divided between Italian and foreign gaming operators, based on the study of the information and data analytically illustrated in the description of the work methodology. 

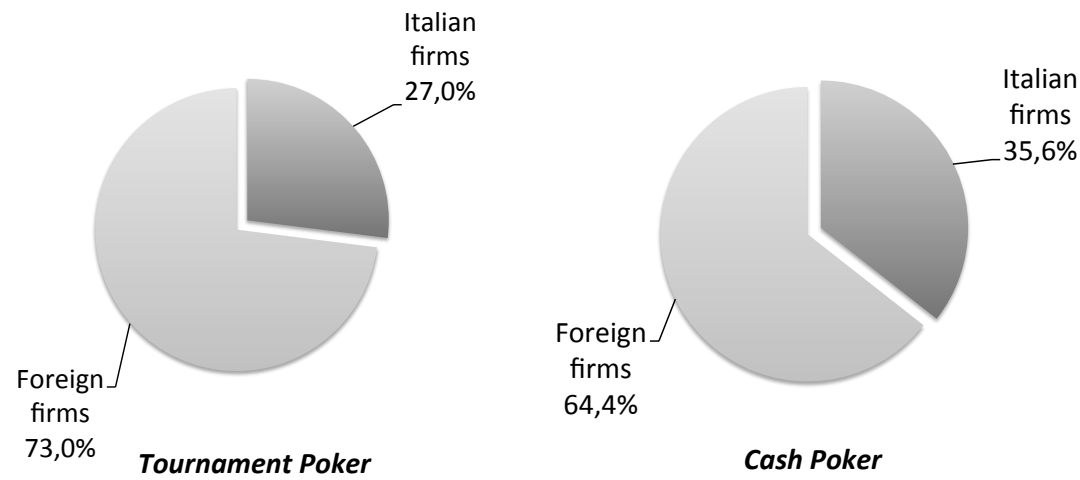

Figure 4. The results of the empirical research. Gross Gambling Revenue in the on line poker industry in Italy: breakdown by nationality of companies (Italian/Foreign). 2018 (Percentage data)

Source: our elaboration on data from Italian Customs and Monopoly Agency and Agimeg.

From Figure 4, in which the results of this analysis are graphically summarized, it emerges that the foreign companies have now established themselves as market leaders, controlling almost three-quarters of the GGR of on line tournament poker, and 64.4 percent of the GGR of on line cash poker. The results are naturally connected to the dominant position taken in the market by the foreign group Pokerstar, in a similar way to what has happened internationally.

If we analyze the development strategies of foreign companies in the Italian market, it emerges that they fall within a broader scope of choices, which sees Italy as one of the many gaming markets needed to reach adequate betting levels. A pool of players from a single country are indeed, very often, too small to allow gambling operators to make good levels of profit. This leads companies to exploit the skills gained in the field of gambling by entering, as quickly as possible, into new betting markets, in order to increase the number of actual and potential customers, thus benefiting from at once greater player liquidity (where legally possible) and obvious cost savings, that are linked to an exploitation of geographic economies of scope.

\subsection{Internet Pure Players Vs. Multichannel Firms in the on Line Poker Industry in Italy}

A final aspect examined through the empirical investigation helps to understand even more the particular competitive dynamics that characterize the on line poker industry in Italy.

As already mentioned, the development of Internet gambling has led in many countries to a joining up in the gambling industry of new operators that have been able to circumvent the high barriers that prevent entry into a sector consisting of huge investments that are necessary to manage a physical distribution network. The commercial disintermediation process caused by the legalization of Internet gambling has, because of this, facilitated the affirmation in Italy of a series of digital newcomers. In particular, within the poker game, which in Italy is offered by licensed gambling operators only through the Internet, it has happened that some 'Internet pure players' have quickly conquered relevant market positions, that make the on line market the exclusive domain for their activities.

Alongside the Internet pure players, there are also several incumbent companies, that have been active for a long time in the Italian gambling industry via the brick-and-mortar network. For these companies the use of the Internet has made it possible to reach the customer for the sale of a series of traditional games through a digital sales channel - that is complementary to the physical one - and also to offer to the clients new types of on line games, such as poker. They have therefore adopted a multichannel distributive approach, which exploits in a combined way the advantages offered by the two different sales channels (on line and physical).

To analyze this aspect in more depth, empirical research aimed at examining - always in relation to the companies that have the license issued by the Italian Customs and Monopoly Agency for remote gambling active at the end of 2018 - the GGR that is divided between 'Internet pure players' and 'Multichannel firms' in the on line poker market. In this case information and data has also been used that is indicated in the description of the work methodology. The classification of operators, in particular, was carried out based on the verification of the possession of the sole license for remote gambling (Internet pure players) or the joint ownership of the remote gambling license and the license for the sale of games through the land-based distribution channel (Multichannel firms). 

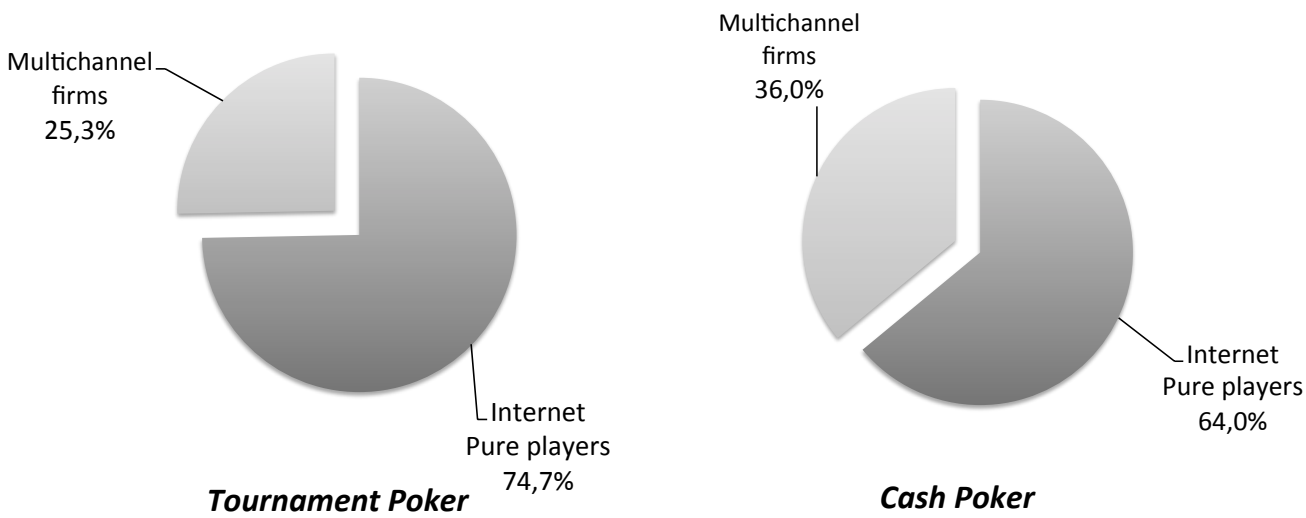

Tournament Poker $74,7 \%$

Figure 5. The results of the empirical research. Gross Gambling Revenue in on line Poker industry in Italy: Multichannel firms vs. Internet Pure Players. 2018 (Percentage data)

Source: our elaboration on data from Italian Customs and Monopoly Agency and Agimeg.

From Figure 5, in which the results of the analysis are graphically shown, it emerges that the Internet pure players overall control around 75 percent of the GGR of on line tournament poker, and 64 percent of the GGR of on line cash poker. The results are connected to those previously described relating to the different nationalities of the companies operating in the market. The Internet pure players are in fact in most cases foreign operators and new entrants who have exploited the potential of the web to replicate the gaming offers in the Italian market that are already offered exclusively via the Internet in other countries. Among these is the Pokerstars Group which occupies, as reported, a dominant position in the market. Alongside the foreign operators, there are few Italian companies that have adopted an Internet pure player strategy, and they are mainly of small or medium size and operate only in Italy, thanks to the adhesion to the network platforms. If we examine more closely the activities carried out by the Internet pure players, the market approach is focused mainly on very few types of on line gaming. For the Internet pure foreign players, in particular, this market strategy is linked to the desire to enhance the capacities matured in other countries in the management of Internet gambling technologies, with the aim of achieving transnational leadership in one or a few of the on line gambling sectors.

The multichannel distribution approach is adopted, instead, mainly by incumbent Italian companies, which after many years of operating games through the land-based distribution channel, act almost exclusively in the national market. For these companies, entering the on line poker industry is part of a broader strategy of diversification in the range of products offered to the customer, realized by introducing, in addition to the types of betting offered through betting shops, those that can only be provided via the Internet. Their core business, therefore, still remains the 'physical market', represented by the sale of traditional games (Sport betting, Bingo, Horse-racing betting, Scratch and win, Lottery, Lotto, etc.) and the game of poker appears to be a market of secondary importance in their business growth strategies (Note 11).

\section{Conclusions}

The analysis carried out has made it possible to understand the impact that the gaming characteristics of Internet poker and the new regulations have had on the market evolution of the Italian on line poker industry. The results of the research, having highlighted the peculiarities of this specific gaming market in respect to those of other gambling sectors, provide interesting indications to policy makers in the field of the regulation of on line poker and also brings out interesting implications of a managerial nature. These can be used by the managers of gambling operators to devise competitive strategies more consistent with the specific characteristics of the game of poker, and therefore more targeted and efficient.

First of all, it emerged that the rules that authorized the on line sale of poker games in Italy impacted on the gaming experience and betting levels in a different way from that of other countries. The possibility for players to access virtual gaming tables via the Internet has, in fact, reconfigured a market which, until 2008, had been very small, given the presence of only four land based casinos authorized to offer poker games (concentrated in the north of Italy). This has transformed a niche business, accessible by a limited number of players, and mainly with a high income, into one for the masses.

However, examination of the trend of the market data of the Italian on line poker industry has also shown that an initial accelerated sales development was followed by a marked reduction in gaming levels. In this regard, the 
survey has allowed us to show that a lack of development of the Internet poker market in Italy seems to be linked to the distinctive features of poker games, especially if we consider this together the effects of some regulatory provisions issued by the Italian legislator.

In the specific, the analysis has allowed us to highlight the fact that poker can be classified as a game of skill. This particular feature of the game means that players, in order to increase their chances of success, must make significant personal investments of time in learning the codes and gaming strategies. The potential market for these types of games is, therefore, more limited than that of games that are based exclusively on random elements and do not require the possession of specific previous skills. Elaboration of market data, in this regard, has shown that the sale of poker games in Italy has been affected by the competition from on line casino games which, due to their nature as 'pure games of chance', are characterized by greater ease and speed of play. Considering, however, that on line casino games are also characterized by a higher potential risk of gambling addiction and by lower pay-out rates for the players in respect to on line poker (Gainsbury, Suhonen \& Saastamoinen, 2014), it could have potential positive effects for the Italian player base to make part of the bets transit from on line casinos games to poker games.

The study also revealed another aspect linked to the distinctive nature of poker that has indirectly affected the development of the sector in Italy. As highlighted, Internet poker is a 'player-versus-player game', that is, it requires the simultaneous presence of several players at virtual gaming tables. This gives to remote gambling a more pronounced character of entertainment and socialization (differentiating it from other games that are essentially based on individual forms of behavior), and for this reason it is more in line with the aims that have guided the process of the legalization of Internet gambling by the Italian regulatory body (Autonomous Administration of State Monopolies, 2012b). Therefore poker - unlike those games for which you can bet regardless of the presence of other players - depends on a high number of players connected via the Internet at all hours of the day to reach a level of player liquidity that is sufficient enough to offer a satisfying gaming experience. In fact, the countries in which on line poker is most widespread are precisely those in which high levels of player liquidity have been reached, thanks to the possibility of proposing a large number of players across time zones through international liquidity sharing. Analysis of the regulation of the Italian market, however, has brought to light - despite the attempts of collaboration started in the last years between controlling institutions of the gambling market of some European countries - the fact that it is still forbidden to share through Internet Italian poker players with those of different nations. This has certainly limited international 'liquidity pooling' that is critical to the success of on line poker, and thus holding back sales growth in the sector.

The particular nature of Internet poker is also influencing the competitive strategies of on line gambling operators in Italy. Analysis has allowed us in this regard to show that the characteristics of on line poker are conditioning the competitive dynamics of the sector in a different way to that compared with other types of on line betting. Indeed, the empirical survey has shown that - similar to what happens abroad - almost all on line poker rooms (licensees and sub-licensees/poker skins) active in Italy at the end of 2018 (153 out of 156), to achieve a high player liquidity joined gaming networks that connect customers of multiple gaming operators through specialized software platforms. This has given rise to competition that has developed on several closely linked levels. A first level of competition occurs between small sub-licensee companies - poker skins - that can sell games via the Internet thanks to affiliation with an authorized dealer. This affiliation, with which you can adhere to the licensee's software platform, allows you to create an on line poker room that can be personalized with their brand and allows shared liquidity with other operators. This minimizes initial investments required to enter the business, thus focusing resources on player acquisition and retention strategies. A second level of competition is that which affects direct licensed gaming operators. For these companies, participation in the network is mainly driven by the need to share a critical mass of players necessary to create a satisfying gaming experience. Thus, on the one hand, they compete with other poker rooms for the acquisition of new players, including those on the network to which they belong, and on the other they compete with other licensed operators in trying to acquire new sub-licensed poker skins. Finally, a third level of competition occurs between gaming platforms. They, whether operating through a 'stand alone' approach, or acting with a 'network approach', are competing for the acquisition of new players. The companies that manage the gaming networks also compete with each other in trying to make their software platforms have the highest number of gaming operators, increasing player liquidity and, therefore, becoming more attractive both for players, and for other poker rooms not affiliated with the network.

In short, it emerges a competition in the on line poker industry that differs from that of other categories of game. In this regard, the results of this empirical research have allowed us to examine other aspects that characterize 
the competitive strategies of on line poker gambling operators in Italy. In fact, it has emerged that new rules introduced in Italy in 2006 opened up the Italian market, hitherto characterized by a closed and oligopolistic structure, to foreign gambling operators. In particular, calculations of the sales data have highlighted the dominant position assumed in the sector by the Pokerstar group, which is also the leader in the on line poker industry at an international level. As pointed out, the decision of foreign companies to enter the Italian market is part of a broad international growth strategy, driven by the objective of increasing the number of overall customers, thus benefiting from a continuous augmentation of gaming turnover and significant economies of scope, in addition to greater player liquidity (where legally possible). The in-depth analysis has also revealed that, in most cases, new entrants are 'Internet pure players' who have exploited the potential of the web to replicate in the Italian market the offer of on line gaming already available in other countries. The survey also showed that these foreign Internet operators have adopted a focused market approach, guided by the goal of achieving transnational leadership in one or more Internet gambling sectors. Instead unlike foreign companies, it has emerged that Italian companies active in the on line poker industry are, almost exclusively, incumbent companies that have been operating in the national gambling market for years through the land-based distribution channel. For these companies the entry into the on line poker market, and more generally into the Internet gambling industry, falls within the ambit of a multi-channel distribution strategy for which the core business still remains the sale of games using the physical distribution channel. Remote gambling is more aimed at reaching the brick and mortar network customers' with a new complementary sales channel, thus also allowing the proposal of new on line games.

\section{References}

Agimeg - Journalistic agency on the gambling market. (2017). Poker online: liquidità internazionale “congelata”. Spunta l'ipotesi di una piattaforma tecnologica unica, August 12th. Retrieved from https://www.agimeg.it/pp/poker-online-liquidita-internazionale-congelata-spunta-lipotesi-piattaforma-tecno logica-unica

Agimeg - Journalistic agency on the gambling market. (2019a). Poker e giochi d'abilità a torneo, nel 2018 mercato in calo dell'1,2\% con una spesa di 82 milioni di euro. Ecco come si sono divisi il mercato $i$ principali operatori, Dati Italia, January 7th. Retrieved from https://www.agimeg.it/pp2/poker-e-giochi-dabilita-a-torneo-nel-2018-mercato-in-calo-dell12-con-una-spesa -di-82-milioni-di-euro-ecco-come-si-sono-divisi-il-mercato-i-principali-operatori

Agimeg - Journalistic agency on the gambling market. (2019b). Poker cash, nel 2018 spesa in calo del 6,7\%. Ecco come si sono divisi il mercato $i$ principali operatori, Dati Italia, January 7 th. Retrieved from https://www.agimeg.it/datitalia/poker-cash-nel-2018-spesa-in-calo-del-67-ecco-come-si-sono-divisi-il-merc ato-i-principali-operatori

Agimeg - Journalistic agency on the gambling market. (2019c). Casinò: nel 2018 incassati 243, 7 milioni di euro, il $63,7 \%$ della raccolta dalle slot, Dati Italia, January 7 th. Retrieved from https://www.agimeg.it/datitalia/casino-nel-2018-incassati-2437-milioni-di-euro-il-637-della-raccolta-dalle-s lot

Autonomous Administration of State Monopolies. (2012a). Il gioco a distanza al 31 maggio 2012, Analisi dei dati. Comunicato stampa. Retrieved from http://www1.agenziadoganemonopoli.gov.it/files_monopoli/GIOCHI/GIOCO-A-DISTANZA/COMUNICA TI/IL-GIOCO-A-DISTANZA-31-05-2012-Analisi-dei-dati.pdf

Autonomous Administration of State Monopolies. (2012b). Il gioco a distanza. Descrizione. Retrieved from https://www.adm.gov.it/portale/monopoli/giochi/gioco_distanza

Busch, P. T. (2015). Piecemeal State Legislation: The Wrong Way to Divide the Internet Poker Pie. Cardozo Arts \& Entrertainement Law Journal, 33(1), 181-209. Retrieved from https://heinonline.org

Customs and Monopoly Agency. (2018). Libro Blu 2017. Organizzazione, statistiche, attività. Retrieved from https://www.adm.gov.it/portale/documents/20182/536133/ADMLibroBlu-2017-v2.pdf/0c4b31c2-46c9-447 3-b5a5-b792a32da6ea

DeDonno, M. A., \& Detterman, D. K. (2008). Poker Is a Skill. Gaming Law Review and Economics, 12(1), 31-36. https://doi.org/10.1089/glr.2008.12105

Eroukmanoff, V., Costes, J. M., \& Tovar, M. L. (2014). Les joueurs de poker, une population présentant un profil particulier? Paris: Observatoire des jeux (ODJ). Retrieved from https://www.economie.gouv.fr/files/note_3_-_les_joueurs_de_poker.pdf 
Fidone, G., \& Linguiti, A. (Eds.). (2013). La disciplina dei giochi in Italia tra monopolio pubblico e mercato. Napoli, Italia: Giuffrè Editore.

Fiedler, I., \& Rock, J. P. (2009). Quantifying skill in games - Theory and empirical evidence for poker. Gaming Law Review and Economics, 13, 50-57. http://dx.doi.org/10.1089/glre.2008.13106

Fiedler, I., \& Wilcke, A. C. (2012). The Market for Online Poker. UNLV Gaming Research and Review Journal, 16(1), 5-18. Retrieved from https://digitalscholarship.unlv.edu/grrj/vol16/iss1/1

Forrest, D. (2012). Online Gambling: An Economics Perspective. In R. J. Williams, R. T. Wood, \& J. Parke (Eds.), Routledge International Handbook of Internet Gambling (pp. 29-45). New York, NY: Routledge.

Gainsbury, S. (2012). Internet gambling: Current research findings and implications. New York: Springer.

Gainsbury, S., \& Wood, R. (2011). Internet gambling policy in critical comparative perspective: The effectiveness of existing regulatory frameworks. International Gambling Studies, 11(3), 309-323. http://dx.doi.org/10.1080/14459795.2011.619553

Gainsbury, S., Wood, R., Russell, A., Hing, N., \& Blaszczynski, A. (2012). A digital revolution: Comparison of demographic profiles, attitudes and gambling behaviour of Internet and non-Internet gamblers. Computers in Human Behaviour, 28(4), 1388-1398. http://dx.doi.org/10.1016/j.chb.2012.02.024

Gainsbury, S.M., Russell, A., Hing, N., Wood, R., Lubman, D., \& Blaszczynski, A. (2015). How the internet is changing gambling: findings from an Australian prevalence survey. Journal of Gambling Studies, 31(1), 1-15. http://dx.doi.org/10.1007/s10899-013-9404-7.

Gainsbury, S.M., Suhonen, N., \& Saastamoinen, J. (2014). Chasing losses in online poker and casino games: Characteristics and game play of Internet gamblers at risk of disordered gambling. Psychiatry Research, 217(3), 220-225. http://dx.doi.org/10.1016/j.psychres.2014.03.033

Grohman, C. (2006). Reconsidering regulation: A historical view of the legality of Internet poker and discussion of the Internet gambling ban of 2006. Journal of Legal Technology Risk Management, 1, 34-74. Retrieved from https://papers.ssrn.com/sol3/papers.cfm?abstract_id=989685

Hannum, R. C., \& Cabot, A. N. (2009). Toward Legalization of Poker: The Skill vs. Chance Debate. UNLV Gaming Research \& Review Journal, 13(1), 1-20. Retrieved from https://digitalscholarship.unlv.edu/grrj/vol13/iss1/1/

Heitner, D. (2017). Largest Online Poker Company Sees Surge In Sports And Online Gambling. Retrieved from www.forbes.com

Hing, N., Gainsbury, S., Blaszczynski A., Wood, R., Lubman, D., \& Russel, A. (2014). Interactive Gambling. Centre for Gambling Education \& Research, Southern Cross University. Retrieved from $\mathrm{http}: / / \mathrm{www}$. gamblingresearch.org.au/home/interactive+gambling+pdf

Howard, S. (2006). Moneymaker method can show the way to a fortune. Retrieved from https://www.thetimes.co.uk/

Koch, S. (2015). Liquidity pooling critical to the success of online poker. Gaming Intelligence Quarterly, 1, 66-67. Retrieved from https://www.ifrahlaw.com/wp-content/uploads/2015/05/document.pdf

Mataluni, F. (2013). La disciplina Italiana in materia di giochi e scommesse. In G., Fidone, \& A. Linguiti (Eds.), La disciplina dei giochi in Italia tra monopolio pubblico e mercato (pp. 61-140). Napoli, Italia: Giuffrè Editore.

Miller, K. C. (2013). Public Policy and the Inevitability of Internet Gambling. Drake Law Review Discourse, 61(1), 1-34. Retrieved from https://heinonline.org

Moreau, A., Chabrol, H., \& Chauchard, E. (2016). Psychopathology of online poker players: Review of literature. Journal of Behavioral Addictions, 5(2), 155-168. https://doi.org/10.1556/2006.5. 2016.035

Morgan-Busher, M. (2012). Business, Models for Online Gambling. In R. J. Williams, R. T. Wood, \& J. Parke (Eds.), Routledge International Handbook of Internet Gambling (pp. 59-83). New York, NY: Routledge.

Mudrík, M. (2017). Moneymaker effect and his marketing impact to poker boom. Economy \& Society \& Environment, 2, 1-7. Retrieved from http://www.exclusiveejournal.sk

Pandimiglio, A., \& Spallone, M. (2012). La valutazione economica delle innovazioni fiscali: metodologia e anticipazioni, CASMEF Working Paper Series, Luiss Guido Carli. Retrieved from http://static.luiss.it/RePEc/pdf/casmef/1108.pdf 
Parke, J., \& Griffiths, M.D. (2007). The role of structural characteristics in gambling. In G. Smith, D. Hodgins \& R. Williams (Eds.), Research and Measurement Issues in Gambling Studies (pp. 211-243). New York: Elsevier.

Pilling, L., \& Bartlett, W. (2012). The Internet Gambling Industry. In R. J. Williams, R. T. Wood, \& J. Parke (Eds.), Routledge International Handbook of Internet Gambling (pp. 48-58). New York, NY: Routledge.

Sbordoni, S. (2010). Giochi concessi e gioco on line. Roma, Italia: Istituto Poligrafico dello Stato.

Schiavone, P. (2010). The Rise of Online Gaming: The Dominant Factors of Poker \& The Fall of The UIGEA and its Predecessors. Law School Student Scholarship, 52. Retrieved from https://scholarship.shu.edu/student_scholarship/52

Statista. (2018). Market value of online gambling worldwide 2017 and 2024. Sport \& Recreation, Gambling. Retrieved from https:/www.statista.com/statistics/270728/market-volume-of-online-gaming-worldwide/

Williams, R., Wood, R., \& Parke, J. (2012). History, Current Worldwide Situation, and Concerns with Internet Gambling. In R. J. Williams, R. T. Wood, \& J. Parke (Eds.), Routledge International Handbook of Internet Gambling (pp. 3-25). New York, NY: Routledge.

Wood, R. T., \& Williams, R. J. (2007). Internet Gambling: Past, Present, and Future. In G. Smith, D. C. Hodgins, \& R. J. Williams (Eds.), Research and Measurement Issues in Gambling Studies (pp. 491-514). Boston: Elsevier.

\section{Notes}

Note 1. This argument does not enter into the aims of this study. For a greater analysis of this theme, a recent review of the "Psychopathology of On line Poker Players" (Moreau, Chabrol \& Chauchard, 2016) can be referred.

Note 2. When referring to the game of poker, different variants can be highlighted. The most frequently played and most popular poker game in the world is 'Texas Hold'em'. Other variations also popular are: Omaha, Stud Poker, Manila, Draw Poker and Razz (Mudrík, 2017).

Note 3. The list of legal operators is made public by the Customs and Monopoly Agency.

Note 4. As described in more detail during the course of this work, in the Italian regulated Internet gambling industry not only companies that have a direct license issued by the Customs and Monopoly Agency can operate, but also sublicensed companies, known as poker skins, affiliated with an authorized dealer.

Note 5. Article 38 of the Bersani Decree, Legislative Decree 4 July 2006, n. 233, converted into with 1. 4 August 2006, n. 248.

Note 6. The main differences between these two types of poker are described in the next paragraph. It is also specified that the total amount wagered of the on line tournament poker also includes a residual share relative to other minor skill games in tournament form.

Note 7 . The probability of winning in this gaming category is decided by the legislator. It should be pointed out that the pay-out levels of on line casino games are lower than those of poker.

Note 8. Only for sports bets the on line sales channel has developed considerably and, in 2017, exceeded in Italy the physical level both in terms of amount wagered that of GGR (our processing of data from the Customs and Monopoly Agency).

Note 9. Actually, another gaming category offered exclusively via the Internet is that of Betting Exchange, which was introduced in Italy in 2014. This is a sports betting mode where players can play the role of bettor or banker and the licenced agency acts as an intermediary, merely putting into contact, exclusively through the digital platform and anonymously, individual bettors (Pandimiglio \& Spallone, 2012). A closer look at the Betting Exchange, shows that, while representing an innovation in the field of games in Italy, it is nothing more than an alternative way to place sports bets. While having rapidly developed in the Italian market, the Betting Exchange represents a variant of residual sports betting, if compared with the sales data of sports betting of the traditional type.

Note 10. It should also be noted that for on line casino games (and not for poker games) players can decide alternatively to play through the 'Apparatuses for entertainment' (Videolotteries and physical Slot machines) present at the betting shops widely distributed throughout the territory, even if these types of games are partially 
different from those offered on line.

Note 11. For the sake of completeness, it should be noted that alongside the Italian companies, also some foreign companies have adopted a multi-channel approach, even if they control overall a more limited share of sales in the on line poker market, compared with that of foreign Internet pure players.

\section{Copyrights}

Copyright for this article is retained by the author(s), with first publication rights granted to the journal.

This is an open-access article distributed under the terms and conditions of the Creative Commons Attribution license (http://creativecommons.org/licenses/by/4.0/). 